\title{
Acknowledgement to the Reviewers
}

The editor-in-chief and associate editors wish to express their gratitude to the following individuals who have graciously accepted responsibility for reviewing manuscripts during 1996.
S. Abbs
R. Adolfson
M.R. Altherr
P. Astolfi
L. Atwood
J. Badner
I. Barrai
M.D. Benson
J. Bertranpetit
H. Bickeböller
D.T. Bishop
E.M. Bleeker-Wagemakers
E. Boerwinkle
Z. Brahmi
D.J.H. Brock
L. Brzustowicz
J. Burn
A. Cao
J.-J. Cassiman
R. Chakraborty
A. Chakravarti
S.W. Cheung
D.H.K. Chui
M. Cicardi
E. Claus
J.F. Crow
J. D’Amaro
S.P. Daiger
R. Deka
A. DeStefano
B. Devlin
EJ. Devor
M. Devoto
S.R. Dlouhy
C.B. Eap
H.J. Edenberg 
A.W. Ericksson

X. Estivill

C. Falk

S.V. Faraone

M.R. Farlow

T. Faroud

L.A. Farrer

R.E. Ferrell

R. Fine

L. Forman

R.R. Frants

J.P. Fryns

T.W. Garvey

T. Gedde-Dahl

A.D. Geurts van Kessel

A. Goate

H.W. Goedde

L.R. Goldin

D. Goldman

G. Golmgren

P. Guldberg

S.-W. Guo

W. Gutensohn

B.E. Hainline

DJ.J. Halley

E.T. Harper

S. Hasstedt

E. Hauser

M. Haviland

S. Heath

J. Hecht N. Heerema M.E. Hodes S.E. Hodge J. Hopper S. Jacobson L. Jorde M.I. Kamboh B.J. Keats T. Keith J. Kere B.-S. Kerem

A. Kessling

J.R. Kidd

K.K. Kidd

W.J. Kimberling

B. Knowlers

J. Knowles

D.K. Lahiri

J.-M. Lalouel

C. Lewis

M. Losekoot

G.V. Louie

M. Macek, Jr.

K. Madan

M. Mannens 


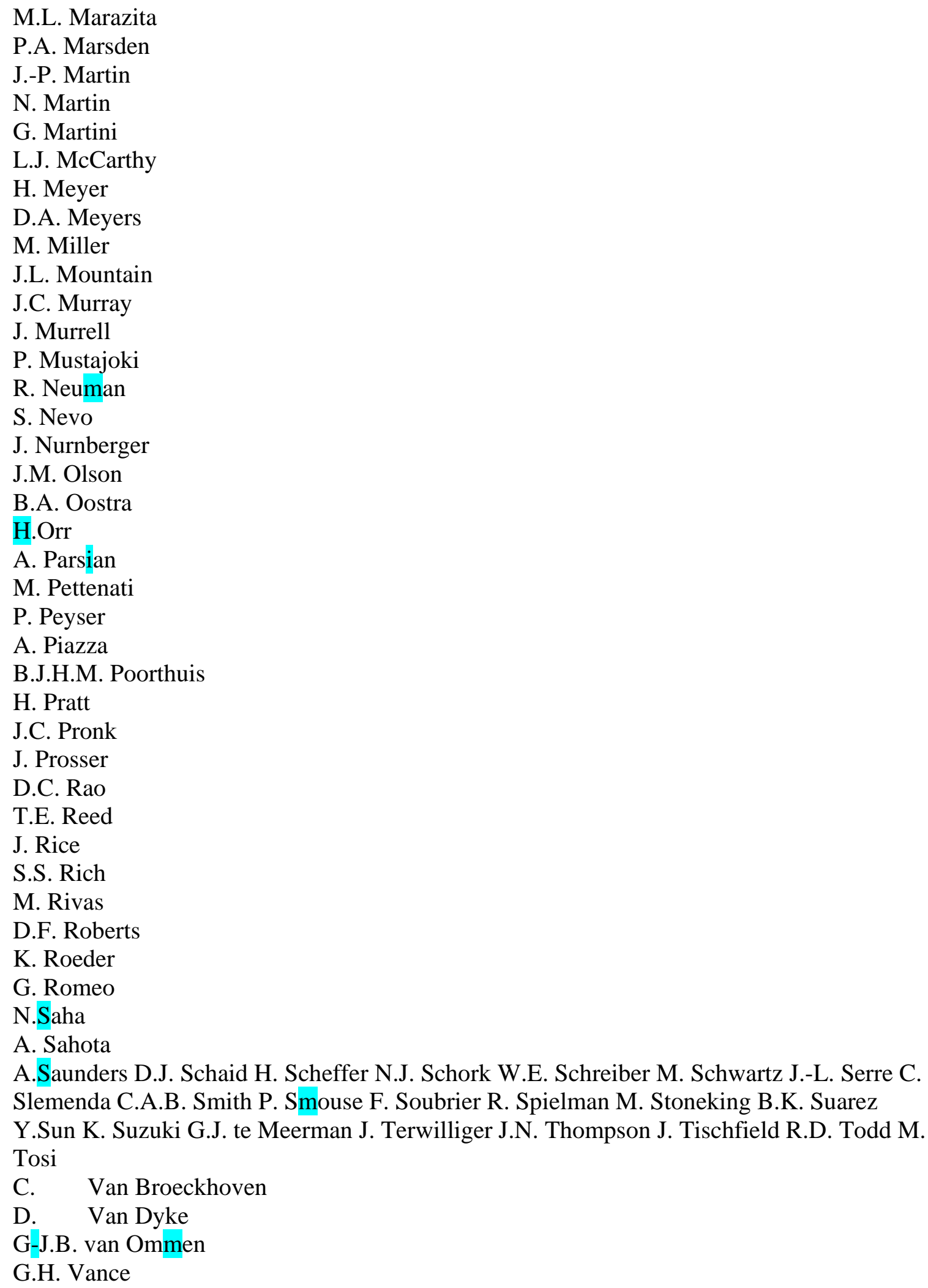


J.M. Vance R.S. Verma M. Warburg R. Ward R.H. Ward J.S. Waye J. Weatherall J.L. Weber A. Weder D.E. Weeks B.S. Weir K. Weiss E.M. Wijsman D. Williams K. Young L.Yu M.A. Zago 